\title{
A novel category of antigens enabling CTL immunity to tumor escape variants: Cinderella antigens
}

\author{
Ursula J. E. Seidel · Claudia C. Oliveira • \\ Margit H. Lampen · Thorbald van Hall
}

Received: 5 September 2011 / Accepted: 10 November 2011 / Published online: 25 November 2011

(C) The Author(s) 2011. This article is published with open access at Springerlink.com

\begin{abstract}
Deficiencies in MHC class I antigen presentation are a common feature of tumors and allows escape from cytotoxic T lymphocyte (CTL)-mediated killing. It is crucial to take this capacity of tumors into account for the development of T-cell-based immunotherapy, as it may strongly impair their effectiveness. A variety of escape mechanisms has been described thus far, but progress in counteracting them is poor. Here we review a novel strategy to target malignancies with defects in the antigenic processing machinery (APM). The concept is based on a unique category of $\mathrm{CD}^{+} \mathrm{T}$-cell epitopes that is associated with impaired peptide processing, which we named TEIPP. We characterized this alternative peptide repertoire emerging in MHC-I on tumors lacking classical antigen processing due to defects in the peptide transporter TAP (transporter associated with peptide processing). These TEIPPs exemplify interesting parallels with the folktale figure Cinderella: they are oppressed and neglected by a stepmother (like functional TAP prevents TEIPP presentation), until the suppression is released and Cinderella/ TEIPP achieves unexpected recognition. TEIPP-specific CTLs and their cognate peptide-epitopes provide a new strategy to counteract immune evasion by APM defects and bear potential to targeting escape variants observed in a wide range of cancers.
\end{abstract}

This paper is a Focussed Research Review based on a presentation given at the Ninth Annual Meeting of the Association for Cancer Immunotherapy (CIMT), held in Mainz, Germany, 25-27 May, 2011. It is part of a CII series of Focussed Research Reviews and meeting report.

U. J. E. Seidel · C. C. Oliveira · M. H. Lampen · T. van Hall ( $ه)$

Department of Clinical Oncology, K1-P, Leiden University

Medical Center, Albinusdreef 2, 2333 Leiden, The Netherlands

e-mail: T.van_Hall@lumc.nl
Keywords T-cell epitopes associated with impaired peptide processing (TEIPP) · Cytotoxic T lymphocytes (CTL) · Tumor immune escape · Antigen processing · Transporter associated with peptide processing (TAP) . CIMT2011

\section{Introduction}

One immune hallmark of tumors is their ability to evade immune recognition [1]. Among others, a common way to escape is through loss of antigen presentation by MHC class I molecules (MHC-I) [2-6]. Defects in the intracellular processing pathway are often the underlying mechanism of the MHC-I downregulation, e.g. TAP impairment is observed from 10 to $74 \%$, varying with tumor types [2,3,6, 7]. Interestingly, MHC-I downregulation has been associated with progressive disease and is very frequent in metastases of cervical carcinoma, breast cancer, melanoma and Ewing sarcoma $[2,8,9]$. Moreover, several studies found a clinical correlation between MHC-I expression and enhanced survival in different malignancies as cervical cancer and HNSCC [6, 10-12]. Two recent case reports show a strong relation between MHC-I expression on metastatic melanoma lesions and progression of these individual lesions during immunotherapy with IFN- $\alpha[13,14]$. All regressing lesions maintained MHC-I surface expression, whereas progressing metastases were characterized by low levels of MHC-I.

The underlying mechanisms of MHC-I downregulation include loss of genes encoding MHC class I heavy chain and $\beta_{2}$-microglobulin $\left(\beta_{2} \mathrm{~m}\right)$ as in loss-of-heterozygosity $(\mathrm{LOH})$, decreased transcription of MHC-I locus products and defects in components of the antigen-processing machinery (APM) comprising peptide transporter TAP, 
tapasin and proteasome subunits [4]. These different molecular mechanisms were recently classified as "hard" and "soft" defects, referring to irreversible or reversible origin, respectively, by gene-regulators or cytokines as IFN- $\gamma$ [5]. Hard defects in this context are structural changes, as $\mathrm{LOH}$, mutations and deletions in antigen presentation involved genes, mainly located on chromosomes 5 and 16, and in the interferon signal transduction pathway $[6,15]$. Downregulation at transcriptional level and hypermethylation of MHC-I genes as well as oncogene activation represent restorable regulatory defects and are defined as soft defects [5].

These studies on MHC-I defects in cancer support the assumption that down modulation of MHC-I is a result of genetic instability and natural selection by immune pressure of naturally occurring or therapy-induced CTL-mediated killing [3]. So, MHC-I loss variants may arise due to immunological "sculpting" of early tumors enabling these variants to escape immunosurveillance during tumor progression [3].

\section{Discovery of a novel CTL specificity combating immune escape variants}

Conventional anti-tumor CTLs recognize tumor-specific (TSA) or tumor-associated antigens (TAA) presented by MHC-I molecules on the surface of tumor cells. Upon loss of antigen presentation, tumor cells become invisible for recognition by these CTLs and therefore turn resistant to CTL-mediated killing [16]. Since impairment of TAP leads to a limited availability of all peptide precursors in the ER, this dysfunction impacts on the total MHC-I surface levels leading to general impairment of recognition and elimination by anti-tumor CTLs [17].

During the search for approaches to counteract immune escape via this route, the group of Dr. Klas Kärre discovered a $\mathrm{CD}^{+} \mathrm{T}$-cell subset that selectively targets TAP-deficient cells [18]. This T-cell population was raised in mice after immunization with B7.1-expressing TAP-deficient RMA-S lymphoma cells. In further investigations of this phenomenon, we characterized a unique category of CTLs that exclusively recognizes tumor cells with defects in their APM, but not cells with proficient APM [18-26] (Fig. 1). Recognition depended on the $\beta_{2} \mathrm{~m}$ light chain and residual MHC-I molecules on the tumor cells [19]. Restoration of TAP function by gene transfer of TAP subunits or by IFN- $\gamma$ treatment significantly decreased recognition of target cells by these CTLs. Conversely, inhibition of TAP in dendritic cells (DCs) by the varicellovirus-encoded evasion protein UL49.5, which mediates degradation of mouse and human TAP proteins [27], induced recognition of these cells by the novel CTL category [20, 25]. Furthermore, reactivity of these CTLs was clearly T-cell receptor dependent and their phenotype was indistinguishable from that of conventional $\mathrm{CD} 8^{+}$CTLs [19]. These findings implied that specificity of the novel CTL category is based on MHC-I/peptide complexes that are exclusively presented by processing deficient cells. This alternative peptide repertoire emerges due to their APM defects we therefore named the target structures "T-cell epitopes associated with impaired peptide
Fig. 1 Schematic diagram of TEIPP-specific CTL. Tumor cells with defects in the antigenprocessing machinery are recognized by TEIPP-specific CTL, but not tumors with intact processing. TEIPP antigens in mouse models are presented by classical MHC-I (upper part) as well as the non-classical MHC-I Qa-1 molecule (lower part). Qa-1-restricted TEIPP CTL recognize TEIPP peptides on cells with TAP-defects and on cells that lost classical MHC-I heavy chains

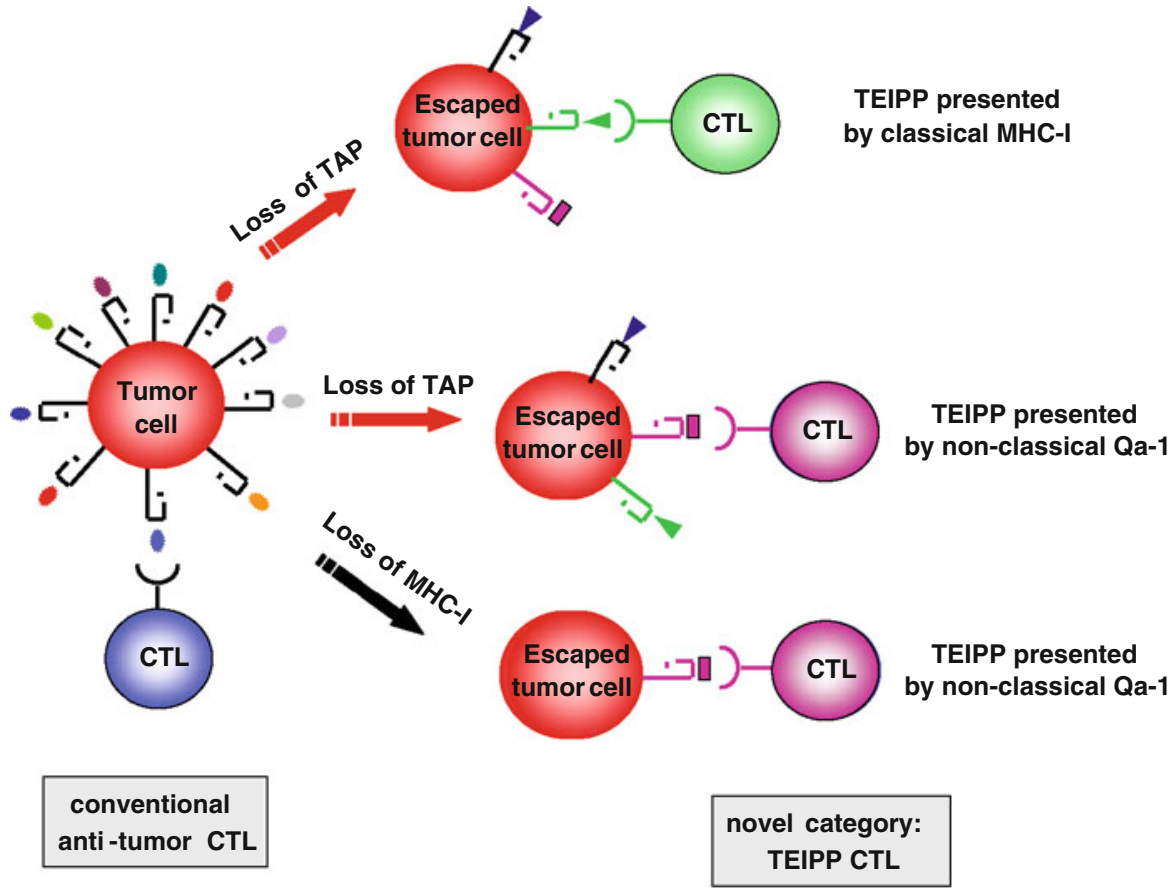


processing" (TEIPP) [19] (Fig. 1). As TEIPP-specificCTLs do not recognize processing-proficient cells, these alternative peptides act as immunogenic neoantigens. Peptide elution studies combined with mass spectrometry and synthetic peptide libraries enabled the molecular identification of the first mouse TEIPP [19]. The peptide recognized by this first CTL clone was not derived from a tumor antigen as such, but from the housekeeping protein TRAM-protein homolog 4 (Trh4 or CerS5) [19]. The epitope was located at the very C-terminus of Trh4, which is an ER membrane spanning fatty acid regulator [28]. Since this protein is ubiquitously expressed, it is logical that every tumor type harboring an APM defect was recognized by this CTL [19]. This implies that TEIPP antigens constitute a novel category of CTL epitopes presented by a broad range of tumors with APM defects.

\section{Why are TEIPP peptides not presented on normal cells?}

Since the peptides recognized by TEIPP-specific CTLs are derived from housekeeping proteins, the question arises why TEIPPs are not presented by processing-proficient cells. Interestingly, TAP-positive tumor cells can be rendered sensitive to TEIPP-specific CTL after treatment with proteasome inhibitors as, e.g. lactacystein or by deficiency of other APM components as, e.g. tapasin [19]. These findings suggest that TEIPP peptides are present within processing intact cells, but are not presented by their surface MHC-I. Moreover, TEIPPs are presented in a TAP-independent manner, although the exact processing pathway and involved enzymes in their liberation still needs to be unraveled. Several alternative processing pathways come into consideration, including signal peptidases, Golgi peptidases as e.g. furin and ER-resident endoproteases which are responsible for cleavage of C-termini [29, 30]. However, how the ligands of the two latter TAP-independent pathways gain access to compartments where MHC-I molecule loading occurs remain elusive.

Recently, we further investigated the fact that the described alternative peptide repertoire does not arise on the cell surface under processing-proficient conditions [25]. We showed that the Trh4 peptide is a stably binding peptide and enhancing availability of MHC-I molecules did not induce TEIPP presentation on the cell surface, indicating that this TEIPP epitope behaves like a normal antigen as such [25]. However, presentation of the Trh4 peptide could be induced by overexpressing Trh4 in processing-proficient cells [25]. Interestingly, increasing recognition by the TEIPP-specific CTL clone correlated with fold of overexpression in target cells. These findings argue against the hypotheses that binding affinity of TEIPP peptides might be
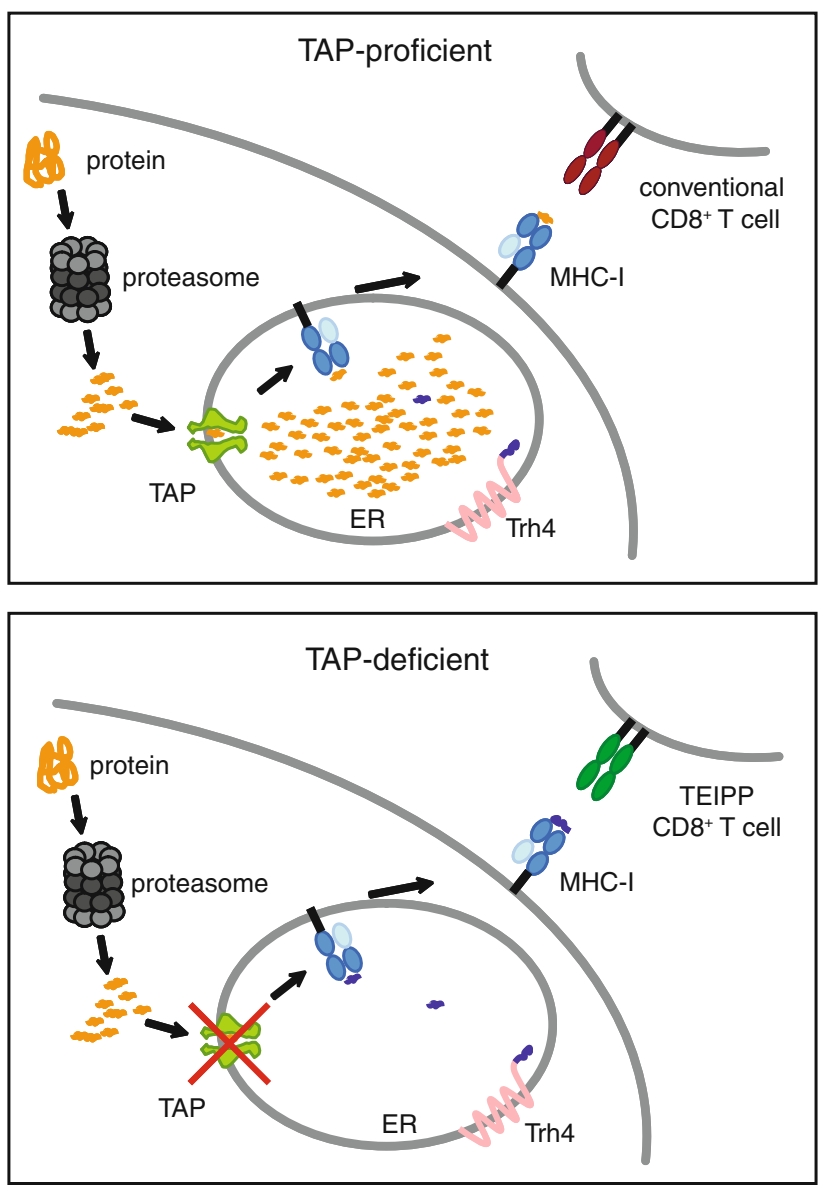

Fig. 2 Schematic illustration to explain why TEIPP peptides fail to be presented by processing-proficient cells. We hypothesize that TEIPP peptides are underrepresented in the ER and lose competition with the vast excess of TAP-pumped peptides under normal conditions. Under TAP-deficiency, those peptides are not transported to the ER and TEIPP peptides get the chance to be presented instead. Binding affinity and stability of the Trh4 epitope with its MHC-I seem sufficient [25]. Note that the exact processing pathway and loading compartment of Trh4 is still unknown

lower than conventional ones and therefore looses competition with high affinity peptides in the ER, but rather, TEIPP peptides are underrepresented in the ER and under normal conditions a vast excess of TAP-pumped competing peptides is present in the ER and prevents TEIPP loading to MHC-I (Fig. 2). Apparently, peptides from alternative processing routes only get the chance to be loaded when TAP is not in optima forma. In other words, TAP behaves like a strong barrier for alternative peptides, like TEIPP.

Interestingly, thymus epithelial cells from wildtype mice, in contrast to those from TAP-knockout mice, were not recognized by the TEIPP-specific CTL clone, albeit the antigen is present in all thymic subpopulations [25]. This finding is in line with the main characteristic of TEIPPs, namely the exclusive emergence on processing deficient cells. As a consequence, TEIPP-specific T cells are thought 
to prevent negative selection in the thymus in normal mice. Furthermore, they are likely to be highly affine for TEIPPs, unlike other $\mathrm{T}$ cells recognizing tumor antigens, which are curtailed by the expression in thymus epithelial cells.

\section{TEIPPs are presented by classical and non-classical MHC-I molecules}

The first molecular defined TEIPP is derived from Trh4 and is presented by the classical MHC-I molecule H2- $\mathrm{D}^{\mathrm{b}}$. However, several other TEIPP-specific $T$ cells have been isolated and were found to be restricted to the non-classical MHC molecule Qa-1 [19, 21, 26] (Fig. 1). Qa-1, the murine equivalent of human HLA-E, is a virtually non-polymorphic MHC class Ib molecule playing an important role in regulating NK cell reactivity. Qa-1 is predominantly filled with "Qa-1 determinant modifier (Qdm)" peptides, and this complex serves as the ligand for CD94/NKG2A inhibitory receptors expressed by a large fraction of natural killer cells [23, 31-33]. With this receptor, natural killer cells check the integrity of the self-MHC-I on potential target cells. The Qdm peptide is derived from the leader sequences of classical MHC class Ia molecules H-2D and H-2L [34]. Peptide elution studies of Qa-1 in processing-proficient cells showed that up to $70 \%$ of the presented peptides are Qdm peptides [21, 35]. Importantly, Qdm processing strictly depends on TAP function, which transports the proteasome-trimmed leader peptides into the ER [36]. Thus, absence of the predominant ligand Qdm in TAP-impaired conditions leads to the presentation of a replacing peptide repertoire [21]. The absence of Qdm occurred on TAP-deficient tumor cells, but also on cells that lost expression of classical MHC-I heavy chains, which encode Qdm. Qa-1 restricted TEIPP CTL responded to both types of defects (Fig. 1). This implies that human tumors with processing defects as well as tumors with HLA-Ia loss, for instance via $\mathrm{LOH}$, can be targeted by these CTLs. However, functional $\beta 2 \mathrm{~m}$ molecules are still strictly required for surface expression of those epitopes. We found a surprisingly diverse peptide repertoire of more than 100 different peptides in Qa-1 on TAP-deficient cells [21]. The peptides originated from housekeeping proteins within the cell and some of them constituted neoantigens according to the TEIPP concept with the ability to give rise to $\mathrm{CD}^{+} \mathrm{T}$-cell responses. The existence of Qa-1 and HLA-E-restricted CD8 ${ }^{+} \mathrm{T}$ cells was shown before, and they recognized peptides derived from cellular stress-related heat shock proteins and intracellular pathogens [23, 37-39]. These data support the assumption of a role of these MHC class Ib molecules in both innate and adaptive immune responses [40]. Interestingly, TEIPP-specific Qa-1-restricted CTL clones recognized TAP-deficient tumors from different MHC haplotype backgrounds [21] by virtue of the conserved nature of Qa-1/HLA-E. Therefore, Qa-1/HLA-E presented TEIPP antigens fulfill quite some requirements of ideal tumor antigens.

\section{TEIPP antigens do exist in humans}

Alternative peptide repertoires presented by TAP-deficient human cells have been described and provided first indications for availability of TEIPP candidates among them [4143]. Further evidence for existence of TEIPPs in human was shown by the experiments with TAP inhibitors derived from herpesviruses. It is a common strategy of viruses, in particular of the herpes family, to target APM components in order to circumvent immunosurveillance by CTL [44]. Examples of viral proteins targeting TAP are ICP47 (HSV), US6 (HCMV), BNLF2a (EBV), and UL49.5 (varicelloviruses). By introducing UL49.5 via gene transfer in human DCs, TAP activity was successfully inhibited [22]. These human TAP-impaired DCs were used as stimulators for autologous T-cell cultures and the resulting CTLs displayed selective killing of TAP-impaired target cells. These findings formally demonstrate the existence of TEIPP-specific CTLs in the human $\mathrm{CD} 8^{+} \mathrm{T}$-cell pool which are likely to come with a relative high frequency among the precursor population as they are readily detectable on bulk level [22]. Furthermore, in silico predictions for immunogenic TAPindependent HLA-Ia binding peptides and HLA-E peptide elution studies with TAP-deficient cells provided a multiplicity of potential TEIPP candidates. The most immunogenic peptides among them will be defined in current investigations.

Interestingly, a CTL epitope derived from the precursor signal peptide of preprocalcitonin (ppCT) was recently shown to be processed in a TAP-independent manner [45]. The described HLA-A2-restricted CTL clone was isolated from a lung cancer patient and recognizes autologous lung carcinoma cells in which overexpression of ppCT transcripts was detected. Recent data of the group of Dr. Mami-Chouaib show that downregulation of TAP is required to allow presentation of this ppCT peptide [49]. Therefore, we consider this CTL epitope, derived from a primary human tumor, as the first molecular defined human TEIPP.

\section{Potential applications of TEIPP peptides in immunotherapy}

Can TEIPP antigens be exploited like normal tumor antigens? We belief they can. In mouse models, we showed that adoptively transferred TEIPP-specific CTLs was able 


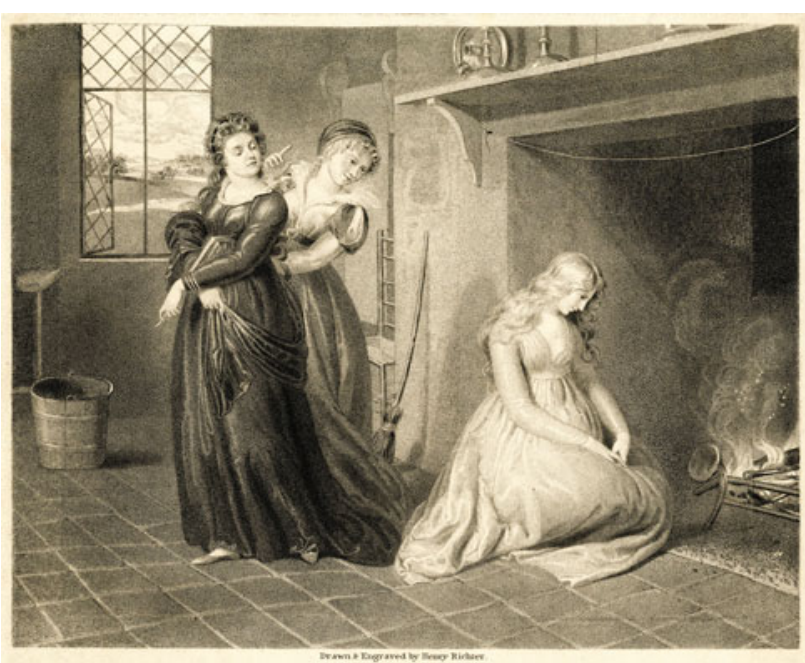

Fig. 3 Stipple etching by Henry James Richter (1772-1857) entitled "Cinderella, or the little glass slipper" (1799), proprietary of the British Museum. The fairy tale figure of Cinderella experienced unjust oppression and ultimately received unexpected recognition, just like TEIPP antigens

to eradicate TAP-deficient tumor cell in vivo and control the outgrowth of a lethal dose [19]. In addition, peptide vaccination studies with the first molecular defined TEIPPspecific CTL epitope induced a protective antitumor CTL response and subsequently prevented outgrowth of the same TAP-deficient tumor [19]. Furthermore, immunization with TAP-deficient DCs mediated protection to TAPdeficient tumor challenge [20]. This DC-based cellular vaccine is characterized by presentation of a variety of endogenous TEIPP antigens by MHC-I molecules. Importantly, in this vaccination strategy, TEIPP antigens do not require to be molecularly identified. Finally, others demonstrated that tumor cell vaccines consisting of TAP-impaired tumor cell lines might also induce immune protection, provided that enough co-stimulation on the tumor cell vaccine is at hand [46, 47]. The applicability of this variety of therapeutic immune interventions shows that TEIPPs can be exploited alike conventional tumor antigens, despite their unconventional character.

We anticipate that TEIPP antigens constitute a novel category of tumor antigens that might contribute to the efficacy of T-cell-based immunotherapy in the future with the aim to prevent outgrowth of AMP-deficient tumor variants $[24,48]$. Tumors with "hard" defects in the APM are likely targets, but also therapy for tumors with "soft" defects might benefit from TEIPP-specific CTL, as these tumors might ignite an initial supply of IFN- $\gamma$ leading to the restoration of "soft" defects. Clearly, TEIPP antigens might complement currently available tumor antigens in order to improve the efficacy of cancer vaccines.

\section{Cinderella as a prototype}

Daydreaming about TEIPP antigens, the folktale story of Cinderella came to our mind (Fig. 3). The fairy tale figure of Cinderella is unjustly oppressed by her stepmother, just like TEIPP antigens are suppressed by a functional TAP. However, her beauty is then openly revealed and she achieves unexpected recognition by Prince Charming at the ball. Once her oppression and neglect are taken away, her full beauty is displayed. We hope that, in parallel, TEIPP antigens will comparably contribute to effective immunotherapy for cancer.

Acknowledgments Authors wish to express their gratitude to Marjolein Sluijter and Bianca Querido for their excellent laboratory assistance for the TEIPP projects, all collaborators who made contributions to this research and the Dutch Cancer Society (project nr 20073897 and 2010-4785) and the Portuguese Foundation for Science and Technology (MCTES) Portugal (SFRH/BD/33539/2008) for financial support.

Conflicts of interest The authors declare that they have no conflict of interest.

Open Access This article is distributed under the terms of the Creative Commons Attribution Noncommercial License which permits any noncommercial use, distribution, and reproduction in any medium, provided the original author(s) and source are credited.

\section{References}

1. Cavallo F, De Giovanni C, Nanni P, Forni G, Lollini PL (2011) 2011: the immune hallmarks of cancer. Cancer Immunol Immunother 60(3):319-326. doi:10.1007/s00262-010-0968-0

2. Hicklin DJ, Marincola FM, Ferrone S (1999) HLA class I antigen downregulation in human cancers: T-cell immunotherapy revives an old story. Mol Med Today 5(4):178-186. doi:S1357-4310(99) 01451-3

3. Khong HT, Restifo NP (2002) Natural selection of tumor variants in the generation of "tumor escape" phenotypes. Nat Immunol 3(11):999-1005. doi:10.1038/ni1102-999

4. Garrido F, Algarra I (2001) MHC antigens and tumor escape from immune surveillance. Adv Cancer Res 83:117-158

5. Garrido F, Cabrera T, Aptsiauri N (2010) "Hard" and "soft" lesions underlying the HLA class I alterations in cancer cells: implications for immunotherapy. Int J Cancer 127(2):249-256. doi:10.1002/ijc. 25270

6. Seliger B (2008) Molecular mechanisms of MHC class I abnormalities and APM components in human tumors. Cancer Immunol Immunother 57(11):1719-1726. doi:10.1007/s00262-008-0515-4

7. Chang CC, Campoli M, Ferrone S (2003) HLA class I defects in malignant lesions: what have we learned? Keio J Med 52(4):220 229

8. Ryu KS, Lee YS, Kim BK, Park YG, Kim YW, Hur SY, Kim TE, Kim IK, Kim JW (2001) Alterations of HLA class I and II antigen expression in preinvasive, invasive and metastatic cervical cancers. Exp Mol Med 33(3):136-144

9. Berghuis D, de Hooge AS, Santos SJ, Horst D, Wiertz EJ, van Eggermond MC, van den Elsen PJ, Taminiau AH, Ottaviano L, Schaefer KL, Dirksen U, Hooijberg E, Mulder A, Melief CJ, Egeler RM, Schilham MW, Jordanova ES, Hogendoorn PC, 
Lankester AC (2009) Reduced human leukocyte antigen expression in advanced-stage Ewing sarcoma: implications for immune recognition. J Pathol 218(2):222-231. doi:10.1002/path.2537

10. Meissner M, Reichert TE, Kunkel M, Gooding W, Whiteside TL, Ferrone S, Seliger B (2005) Defects in the human leukocyte antigen class I antigen processing machinery in head and neck squamous cell carcinoma: association with clinical outcome. Clin Cancer Res 11(7):2552-2560. doi:10.1158/1078-0432.CCR-042146

11. Jordanova ES, Gorter A, Ayachi O, Prins F, Durrant LG, Kenter GG, van der Burg SH, Fleuren GJ (2008) Human leukocyte antigen class I, MHC class I chain-related molecule A, and CD8 +/regulatory T-cell ratio: which variable determines survival of cervical cancer patients? Clin Cancer Res 14(7):2028-2035. doi:10.1158/ 1078-0432.CCR-07-4554

12. Mehta AM, Jordanova ES, Kenter GG, Ferrone S, Fleuren GJ (2008) Association of antigen processing machinery and HLA class I defects with clinicopathological outcome in cervical carcinoma. Cancer Immunol Immunother 57(2):197-206. doi:10.1007/ s00262-007-0362-8

13. Cabrera T, Lara E, Romero JM, Maleno I, Real LM, Ruiz-Cabello F, Valero P, Camacho FM, Garrido F (2007) HLA class I expression in metastatic melanoma correlates with tumor development during autologous vaccination. Cancer Immunol Immunother 56(5):709-717. doi:10.1007/s00262-006-0226-7

14. Carretero R, Romero JM, Ruiz-Cabello F, Maleno I, Rodriguez F, Camacho FM, Real LM, Garrido F, Cabrera T (2008) Analysis of HLA class I expression in progressing and regressing metastatic melanoma lesions after immunotherapy. Immunogenetics 60(8): 439-447. doi:10.1007/s00251-008-0303-5

15. Seliger B, Ruiz-Cabello F, Garrido F (2008) IFN inducibility of major histocompatibility antigens in tumors. Adv Cancer Res 101:249-276. doi:10.1016/S0065-230X(08)00407-7

16. Maeurer MJ, Gollin SM, Martin D, Swaney W, Bryant J, Castelli C, Robbins P, Parmiani G, Storkus WJ, Lotze MT (1996) Tumor escape from immune recognition: lethal recurrent melanoma in a patient associated with downregulation of the peptide transporter protein TAP-1 and loss of expression of the immunodominant MART-1/Melan-A antigen. J Clin Invest 98(7):1633-1641. doi:10.1172/ JCI118958

17. van Endert PM (1999) Genes regulating MHC class I processing of antigen. Curr Opin Immunol 11(1):82-88.

18. Wolpert EZ, Petersson M, Chambers BJ, Sandberg JK, Kiessling R, Ljunggren HG, Karre K (1997) Generation of CD8 + T cells specific for transporter associated with antigen processing deficient cells. Proc Natl Acad Sci U S A 94(21):11496-11501

19. van Hall T, Wolpert EZ, van Veelen P, Laban S, van der Veer M, Roseboom M, Bres S, Grufman P, de Ru A, Meiring H, de Jong A, Franken K, Teixeira A, Valentijn R, Drijfhout JW, Koning F, Camps M, Ossendorp F, Karre K, Ljunggren HG, Melief CJ, Offringa $\mathrm{R}$ (2006) Selective cytotoxic T-lymphocyte targeting of tumor immune escape variants. Nat Med 12(4):417-424. doi:10.1038/ $\mathrm{nm} 1381$

20. Chambers B, Grufman P, Fredriksson V, Andersson K, Roseboom M, Laban S, Camps M, Wolpert EZ, Wiertz EJ, Offringa R, Ljunggren HG, van Hall T (2007) Induction of protective CTL immunity against peptide transporter TAP-deficient tumors through dendritic cell vaccination. Cancer Res 67(18):8450-8455. doi:10.1158/00085472.CAN-07-1092

21. Oliveira CC, van Veelen PA, Querido B, de Ru A, Sluijter M, Laban S, Drijfhout JW, van der Burg SH, Offringa R, van Hall T (2010) The nonpolymorphic MHC Qa-1b mediates CD8+ T cell surveillance of antigen-processing defects. J Exp Med 207(1): 207-221. doi:10.1084/jem.20091429

22. Lampen MH, Verweij MC, Querido B, van der Burg SH, Wiertz EJ, van Hall T (2010) CD8+ T cell responses against TAP-inhibited cells are readily detected in the human population. J Immunol 185(11):6508-6517. doi:10.4049/jimmunol.1001774

23. van Hall T, Oliveira CC, Joosten SA, Ottenhoff TH (2010) The other Janus face of Qa-1 and HLA-E: diverse peptide repertoires in times of stress. Microbes Infect 12(12-13):910-918. doi:10.1016/j.micinf.2010.07.011

24. Lampen MH, van Hall T (2011) Strategies to counteract MHC-I defects in tumors. Curr Opin Immunol 23(2):293-298. doi:10.1016/j.coi.2010.12.005

25. Oliveira CC, Querido B, Sluijter M, Derbinski J, van der Burg SH, van Hall T (2011) Peptide transporter TAP mediates between competing antigen sources generating distinct surface MHC-I peptide repertoires. Eur J Immunol 41(11):3114-3124. doi:10.1002/eji. 201141836

26. van Hall T, Laban S, Koppers-Lalic D, Koch J, Precup C, Asmawidjaja P, Offringa R, Wiertz EJ (2007) The varicellovirus-encoded TAP inhibitor UL49.5 regulates the presentation of CTL epitopes by Qa-1b1. J Immunol 178(2):657-662.

27. Verweij MC, Ressing ME, Knetsch W, Quinten E, Halenius A, van Bel N, Hengel H, Drijfhout JW, van Hall T, Wiertz EJ (2011) Inhibition of mouse TAP by immune evasion molecules encoded by non-murine herpesviruses. Mol Immunol 48(6-7):835-845. doi:10.1016/j.molimm.2010.12.008

28. Riebeling C, Allegood JC, Wang E, Merrill AH Jr, Futerman AH (2003) Two mammalian longevity assurance gene (LAG1) family members, trh1 and trh4, regulate dihydroceramide synthesis using different fatty acyl-CoA donors. J Biol Chem 278(44):4345243459. doi:10.1074/jbc.M307104200

29. NM LarsenMV, Weinzierl A, Lund O (2006) TAP-independent MHC class I presentation. Immunol Rev 2:233-245. doi:10.2174/ 157339506778018550

30. Del Val M, Iborra S, Ramos M, Lazaro S (2011) Generation of MHC class I ligands in the secretory and vesicular pathways. Cell Mol Life Sci 68(9):1543-1552. doi:10.1007/s00018-011-0661-2

31. Braud VM, Allan DS, O'Callaghan CA, Soderstrom K, D'Andrea A, Ogg GS, Lazetic S, Young NT, Bell JI, Phillips JH, Lanier LL, McMichael AJ (1998) HLA-E binds to natural killer cell receptors CD94/NKG2A, B and C. Nature 391(6669):795-799. doi:10.1038/ 35869

32. Rodgers JR, Cook RG (2005) MHC class Ib molecules bridge innate and acquired immunity. Nat Rev Immunol 5(6):459-471. doi:10.1038/nri1635

33. Jensen PE, Sullivan BA, Reed-Loisel LM, Weber DA (2004) Qa-1, a nonclassical class I histocompatibility molecule with roles in innate and adaptive immunity. Immunol Res 29(1-3):81-92. doi:10.1385/IR:29:1-3:081

34. Kraft JR, Vance RE, Pohl J, Martin AM, Raulet DH, Jensen PE (2000) Analysis of Qa-1(b) peptide binding specificity and the capacity of CD94/NKG2A to discriminate between Qa-1-peptide complexes. J Exp Med 192(5):613-624

35. DeCloux A, Woods AS, Cotter RJ, Soloski MJ, Forman J (1997) Dominance of a single peptide bound to the class I(B) molecule, Qa-1b. J Immunol 158(5):2183-2191

36. Lee N, Goodlett DR, Ishitani A, Marquardt H, Geraghty DE (1998) HLA-E surface expression depends on binding of TAPdependent peptides derived from certain HLA class I signal sequences. J Immunol 160(10):4951-4960

37. Lo WF, Woods AS, DeCloux A, Cotter RJ, Metcalf ES, Soloski MJ (2000) Molecular mimicry mediated by MHC class Ib molecules after infection with gram-negative pathogens. Nat Med 6(2):215-218. doi:10.1038/72329

38. Davies A, Kalb S, Liang B, Aldrich CJ, Lemonnier FA, Jiang H, Cotter R, Soloski MJ (2003) A peptide from heat shock protein 60 is the dominant peptide bound to Qa-1 in the absence of the MHC class Ia leader sequence peptide Qdm. J Immunol 170(10):50275033 
39. Pietra G, Romagnani C, Manzini C, Moretta L, Mingari MC (2010) The emerging role of HLA-E-restricted CD8 + T lymphocytes in the adaptive immune response to pathogens and tumors. J Biomed Biotechnol 2010:907092. doi:10.1155/2010/907092

40. Sullivan LC, Clements CS, Rossjohn J, Brooks AG (2008) The major histocompatibility complex class Ib molecule HLA-E at the interface between innate and adaptive immunity. Tissue Antigens 72(5):415-424

41. Henderson RA, Michel H, Sakaguchi K, Shabanowitz J, Appella E, Hunt DF, Engelhard VH (1992) HLA-A2.1-associated peptides from a mutant cell line: a second pathway of antigen presentation. Science 255(5049):1264-1266

42. Wei ML, Cresswell P (1992) HLA-A2 molecules in an antigenprocessing mutant cell contain signal sequence-derived peptides. Nature 356(6368):443-446. doi:10.1038/356443a0

43. Weinzierl AO, Rudolf D, Hillen N, Tenzer S, van Endert P, Schild H, Rammensee HG, Stevanovic S (2008) Features of TAP-independent MHC class I ligands revealed by quantitative mass spectrometry. Eur J Immunol 38(6):1503-1510. doi:10.1002/eji.200 838136

44. Horst D, Verweij MC, Davison AJ, Ressing ME, Wiertz EJ (2011) Viral evasion of $\mathrm{T}$ cell immunity: ancient mechanisms offering new applications. Curr Opin Immunol 23(1):96-103. doi:10.1016/ j.coi.2010.11.005
45. El Hage F, Stroobant V, Vergnon I, Baurain JF, Echchakir H, Lazar V, Chouaib S, Coulie PG, Mami-Chouaib F (2008) Preprocalcitonin signal peptide generates a cytotoxic T lymphocyte-defined tumor epitope processed by a proteasome-independent pathway. Proc Natl Acad Sci USA 105(29):10119-10124. doi:10.1073/ pnas.0802753105

46. Li XL, Liu YY, Knight D, Odaka Y, Mathis JM, Shi R, Glass J, Zhang QJ (2009) Effect of B7.1 costimulation on T-cell based immunity against TAP-negative cancer can be facilitated by TAP1 expression. PLoS One 4(7):e6385. doi:10.1371/journal.pone. 0006385

47. Li XL, Zhang D, Knight D, Odaka Y, Glass J, Mathis JM, Zhang QJ (2009) Priming of immune responses against transporter associated with antigen processing (TAP)-deficient tumours: tumour direct priming. Immunology 128(3):420-428. doi:10.1111/j.13652567.2009.03127.x

48. Vergati M, Intrivici C, Huen NY, Schlom J, Tsang KY (2010) Strategies for cancer vaccine development. J Biomed Biotechnol. doi:10.1155/2010/596432

49. Durgeau A, El Hage F, Vergnon I, Validire P, de Montpreville V, Besse B, Soria JC, van Hall T, Mami-Chouaib F (2011) Different expression levels of the TAP peptide transporter lead to recognition of different antigenic peptides by tumor-specific CTL. J Immunol 187(11):5532-5539. doi:10.4049/jimmunol.1102060 